\title{
The effect of continuous positive airway pressure on total cerebral blood flow in healthy awake volunteers
}

\author{
Theresia I. Yiallourou • Céline Odier • \\ Raphael Heinzer • Lorenz Hirt • Bryn A. Martin • \\ Nikolaos Stergiopulos • José Haba-Rubio
}

Received: 22 September 2011 /Revised: 17 February 2012 / Accepted: 5 March 2012 /Published online: 22 March 2012

(C) Springer-Verlag 2012

\begin{abstract}
Purpose Continuous positive airway pressure (CPAP) is the gold standard treatment for obstructive sleep apnea. However, the physiologic impact of CPAP on cerebral blood flow (CBF) is not well established. Ultrasound can be used to estimate $\mathrm{CBF}$, but there is no widespread accepted protocol. We studied the physiologic influence of CPAP on CBF using a method integrating arterial diameter and flow velocity (FV) measurements obtained for each vessel supplying blood to the brain. Methods FV and lumen diameter of the left and right internal carotid, vertebral, and middle cerebral arteries were measured using duplex Doppler ultrasound with and without CPAP at $15 \mathrm{~cm} \mathrm{H}_{2} \mathrm{O}$, applied in a random order. Transcutaneous carbon dioxide $\left(\mathrm{PtcCO}_{2}\right)$, heart rate (HR), blood pressure (BP), and oxygen saturation were monitored. Results were compared with a theoretical prediction of $\mathrm{CBF}$ change based on the effect of partial pressure of carbon dioxide on CBF.

Results Data were obtained from 23 healthy volunteers (mean \pm SD; 12 male, age $25.1 \pm 2.6$ years, body mass index
\end{abstract}

Theresia I. Yiallourou and Céline Odier contributed equally to this work

T. I. Yiallourou $(\square) \cdot$ B. A. Martin $\cdot$ N. Stergiopulos Ecole Polytechnique Fédérale de Lausanne (EPFL),

Laboratory of Hemodynamics and Cardiovascular Technology

(LHTC),

Building BM-Station 17, Room BM 5128,

1015 Lausanne, Switzerland

e-mail: thiresia.giallourou@epfl.ch

C. Odier $\cdot$ L. Hirt

Neurosciences Department, Centre Hospitalier Universitaire

Vaudois Lausanne(CHUV),

Lausanne, Switzerland

R. Heinzer $\cdot$ J. Haba-Rubio

CHUV, Center for Investigation and Research in Sleep (CIRS),

Lausanne, Switzerland
$21.8 \pm 2.0 \mathrm{~kg} / \mathrm{m}^{2}$ ). The mean experimental and theoretical CBF decrease under CPAP was $12.5 \%(p<0.001)$ and $11.9 \%$ $(p<0.001)$, respectively. The difference between experimental and theoretical CBF reduction was not statistically significant $(3.84 \pm 79 \mathrm{ml} / \mathrm{min}, p=0.40)$. There was a significant reduction in $\mathrm{PtcCO}_{2}$ with CPAP $(p=<0.001)$ and a significant increase in mean $\mathrm{BP}(p=0.0017)$. No significant change was observed in $\mathrm{SaO}_{2}(p=0.21)$ and $\mathrm{HR}(p=0.62)$.

Conclusion Duplex Doppler ultrasound measurements of arterial diameter and $\mathrm{FV}$ allow for a noninvasive bedside estimation of CBF. CPAP at $15 \mathrm{~cm} \mathrm{H}_{2} \mathrm{O}$ significantly decreased CBF in healthy awake volunteers. This effect appeared to be mediated predominately through the hypocapnic vasoconstriction coinciding with $\mathrm{PCO}_{2}$ level reduction. The results suggest that CPAP should be used cautiously in patients with unstable cerebral hemodynamics.

Keywords Continuous positive airway pressure $\cdot$ Cerebral blood flow $\cdot \mathrm{PCO}_{2} \cdot$ Ultrasound

\section{Introduction}

Obstructive sleep apnea syndrome (OSAS) is characterized by repetitive episodes of upper airway obstruction during sleep and results in cessation (apneas) or reduction (hypopneas) in airflow which leads to awakening and the reduction of blood oxygen saturation $\left(\mathrm{SaO}_{2}\right)$. The most widely accepted treatment of OSAS is continuous positive airway pressure (CPAP). CPAP acts as a pneumatic "splint" by producing a positive pressure inside the airway thereby preventing upper airway collapse during sleep. Considering that a rise in intrathoracic pressure increases jugular venous pressure, CPAP could have an effect on cerebral blood flow $(\mathrm{CBF})$ by reducing the cerebral perfusion pressure $[1,2]$. 
Moreover, decreased venous return due to increased intrathoracic pressure may decrease right (and left) filling pressure, which may in turn decrease cardiac output. CPAP use can also induce changes in partial pressure of carbon dioxide $\left(\mathrm{PCO}_{2}\right)$, which has a major impact on $\mathrm{CBF}$, similar to the way in which hypocapnia constricts cerebral arteries and hypercapnia leads to a marked rise of $\mathrm{CBF}$ [3-5]. Changes in $\mathrm{CBF}$ induced by CPAP may have important clinical implications in patients for whom an optimal CBF is mandatory, such as acute stroke patients.

Published data about the effects of CPAP on cerebral hemodynamics are conflicting [6-8]. Various studies have reported an increase $[8,9]$, others a decrease $[7,10]$, and some an insignificant change [6] in CBF. The conflicting results may be due to inaccurate and/or insensitive CBF measurement methods. Furthermore, many of the studies that employed transcranial Doppler ultrasound (TCD) used only flow velocity (FV) and pulsatility index (PI) in the middle cerebral artery (MCA) to estimate total CBF [6-10]. However, TCD measurements do not take into account changes in artery diameter or in cerebral posterior circulation. As a result, it is unclear whether changes in MCA FV accurately reflect total CBF change. A method that takes into account both blood FV and the artery diameter of all vessels supplying blood to the brain is likely to be more accurate. Furthermore, in the previous studies [6-8] only end-tidal $\mathrm{CO}_{2}$ level was monitored. This is an inaccurate measurement technique under the presence of CPAP considering that the expired $\mathrm{CO}_{2}$ is diluted by incoming $\mathrm{CO}_{2}$-free CPAP airflow.

The present study was performed to assess the effect of CPAP on total CBF measured by duplex color Doppler ultrasound (US) using a method, similar to that presented by Schoning et al. [11], incorporating FV and lumen diameter measurements obtained at the left and right internal carotid artery (ICA), vertebral artery (VA), and MCA. These measurements were obtained while transcutaneous carbon dioxide $\left(\mathrm{PtcCO}_{2}\right)$ level was monitored continuously.

\section{Methods}

Healthy, young, nonsmoking volunteers were invited to participate in the study by advertisement at the Centre Hospitalier Universitaire Vaudois and École Polytechnique Fédérale de Lausanne in Switzerland. Volunteers with a history of pulmonary, cardiac or cerebral disease were excluded. The study was carried out in accordance with the Declaration of Helsinki (1989) of the World Medical Association and was approved by the local ethics committee. All subjects gave their informed consent.
Ultrasound measurements

The US measurements were performed with and without CPAP (S8 AutoSet Spirit ${ }^{\mathrm{TM}}$ II, ResMed Inc, Poway, CA, USA) applied at $15 \mathrm{~cm} \mathrm{H}_{2} \mathrm{O}$ through a fitted full face mask MIRAGE QUATTRO ${ }^{\circledR}\left(\operatorname{ResMed}^{\circledR}\right.$, ResMed Inc, Poway, CA, USA) in a randomized order following a structured protocol. Randomization was accomplished by flipping a coin. The measurements were performed during the afternoon at atmospheric pressure at least $2 \mathrm{~h}$ after the last meal and drink with caffeine in a standard room with controlled temperature. All volunteers, who were studied in the supine position with a head tilt of $30^{\circ}$, tolerated CPAP at $15 \mathrm{~cm} \mathrm{H}_{2} \mathrm{O}$ well. The arteries were studied with and without CPAP in the following order: (a) right proximal ICA and VA, (b) left proximal ICA and VA, and (c) right and left MCA.

Peak systolic and end-diastolic FV and arterial diameter were obtained in M-mode [12] for three time points at the left and right ICA and VA using a 5-8 $\mathrm{MHz}$ duplex probe (Echograph Acuson Sequoia 512). Only FV was studied at the MCAs using a 2-4 MHz-pulsed TCD probe of the same manufacturer. $\mathrm{PtcCO}_{2}$ level was monitored with a "Tosca 500" system (Radiometer Basel AG, Basel, Switzerland) using a single sensor applied to the chest. $\mathrm{SaO}_{2}$ and heart rate (HR) were monitored with a finger pulseoximeter (Ohmeda) during the measurement period. Blood pressure (BP) was recorded before and after each test. US measurements under CPAP began after the $\mathrm{PtcCO}_{2}$ level returned to baseline $( \pm 2 \mathrm{mmHg}$ ) or at steady state after at least $15 \mathrm{~min}$ of CPAP use. This time period was sufficient to ensure a steady state as changes in $\mathrm{CBF}$ caused by an alteration in $\mathrm{PCO}_{2}$ level have been found to be completed within $30 \mathrm{~s}$ [13].

\section{CBF calculations}

A single investigator (CO) performed all of the US exams with the exception of two (LH). All velocity and diameter measurements, based on the US images, were performed by two investigators (CO, TY). Exams were reviewed by both investigators to assure that measurements were performed on the same M-mode screen and on the correct vessel within the region of interest. The mean value of both investigators' measurements was used for the calculations. The mean FV in each vessel was calculated by measuring the peak systolic, $\mathrm{FV}_{\text {sys }}$, and end diastolic, $\mathrm{FV}_{\mathrm{dia}}, \mathrm{FV}$ for three cardiac cycles (Eq. 1)

$\mathrm{FV}=\frac{\mathrm{FV}_{\text {sys }}+2 \mathrm{FV}_{\text {dia }}}{3}$

Mean diameter $\bar{D}$ of each vessel for three cardiac cycles was calculated based on the M-mode US measurements [12] 
using a similar equation as Eq. 1, except with FV replaced with the systolic and diastolic diameter. An example of the $\mathrm{FV}$ and diameter measurement obtained at the right ICA is shown in Fig. 1.

Flow rate, $Q$ (millimeter per minute), in each vessel was calculated by (Eq. 2) and total experimental CBF, $\mathrm{CBF}_{\text {exp }}$, was determined by the sum of the flow in the left and right ICAs and VAs assuming a parabolic velocity profile[14] (Eq. 3).

$\mathrm{Q}=\frac{\mathrm{FV}}{2} \times \frac{\pi \bar{D}^{2}}{4}$

$\mathrm{CBF}_{\text {exp }}=Q_{\mathrm{ICAs}}+Q_{\mathrm{VAs}}$

Vascular related results are presented as the average of the left and right vessel measurements for the 23 subjects (i.e., $\left.\mathrm{FV}_{\mathrm{ICA}}=\frac{1}{23} \sum_{n=1}^{23}\left(\mathrm{FV}_{\text {ICAleft }}+\mathrm{FV}_{\text {ICAright }}\right) / 2\right)$.

The following method was used to predict a theoretical change in $\mathrm{CBF}$ given an experimentally measured change in $\mathrm{PtcCO}_{2}$ level. The relationship between CBF $(\mathrm{ml} / \mathrm{min} / 100 \mathrm{~g}$ brain tissue) and arterial $\mathrm{CO}_{2}$ tension (millimeters of mercury) has been quantified in the literature (Fig. 2) [3, 15-21]. Table 1 summarizes the slope of the $\mathrm{CBF}$ to $\mathrm{PCO}_{2}$ curve at baseline $\mathrm{PCO}_{2}$ level based on Fig. 2 and other studies in the literature. The average slope was calculated to be 1.65 , with a maximum and minimum slope value of 3.20 and 0.19 , respectively (standard deviation $=0.92$ ). The average slope was used to determine a theoretical reduction in $\mathrm{CBF}$ in $\mathrm{ml} / \mathrm{min} / 100 \mathrm{~g}$ of brain tissue, $\triangle \mathrm{CBF}_{\text {theor } 100}$, based on the experimentally measured change in $\mathrm{PtcCO}_{2}$ level with and without CPAP $\Delta \mathrm{CBF}_{\text {theor } 100}=$ - slope $\times \Delta \mathrm{PtcCO}_{2}$. The total theoretical change in $\mathrm{CBF}$ was determined $\left(\Delta \mathrm{CBF}_{\text {theor }}=14 \times \Delta \mathrm{CBF}_{\text {theorl00 }}\right)$ assuming that the human brain is approximately 14 times the weight of a Rhesus monkey [21].

The $\mathrm{CBF}_{\text {exp }}$ measurements were used to determine the experimental $\mathrm{CBF}$ reduction $\left(\triangle \mathrm{CBF}_{\text {exp }}\right)$. Positive $\mathrm{CBF}$ reduction values were defined to indicate that total $\mathrm{CBF}$ decreased under $\mathrm{CPAP}$, and vice versa. The average and standard deviation of $\triangle \mathrm{CBF}_{\text {exp }}$ and $\triangle \mathrm{CBF}_{\text {theor }}$ were determined for the 23 subjects based on both investigators measurements.

Statistical analysis

Statistical analysis was conducted with STATA software (version 11; College Station, TX, USA). The variable measured parameters were compared between conditions using a two-tailed paired $t$ test and Mann-Whitney test, where appropriate. The level of significance was set at $95 \%$. Multivariate logistic regression, limited to two variables according to the total number of subjects, was performed with predictors with a univariate result of $p<0.1$. Agreement between investigators was calculated with the Lin's concordance correlation coefficient for agreement on a continuous measure.

\section{Results}

The study group was comprised of 23 subjects (12 male, 11 female) aged from 20 to 30 years (mean \pm SD; $25.1 \pm$ 2.6 years) with a mean body mass index (BMI) of $21.8 \pm$ $2.04 \mathrm{~kg} / \mathrm{m}^{2}$. Thirteen volunteers began the randomized measurement protocol with CPAP. Table 2 shows a summary of the hemodynamic data and results for the CBF calculations with and without CPAP.

With CPAP, FV decreased significantly in the ICA $(0.05 \pm$ $0.05 \mathrm{~m} / \mathrm{s}, p=0.0002)$ and the MCA $(0.038 \pm 0.06 \mathrm{~m} / \mathrm{s}, p=$ $0.009)$, but not significantly at the VA $(0.009 \pm 0.04 \mathrm{~m} / \mathrm{s}, p=$ $0.25)$. Decrease in the ICA diameter was insignificant $(-0.06 \pm$ $0.2 \mathrm{~mm}, p=0.14)$, while decrease in VA diameter was significant $(-0.12 \pm 0.12 \mathrm{~mm}, p<0.001)$. In a multivariate robust regression, with total $\mathrm{CBF}$ reduction as a dependant variable, only ICA FV $(p<0.001)$ remained significant, whereas MCA FV was not significant $(p=0.21)$.

A significant reduction in $\mathrm{PtcCO}_{2}$ under CPAP $(2.6 \pm$ $2.4 \mathrm{~mm} \mathrm{Hg}, p=<0.001)$ and an increase in mean BP $(2.7 \pm$ $3.6 \mathrm{~mm} \mathrm{Hg}, p=0.0017)$ were measured. No significant change in $\mathrm{SaO}_{2}(0.4 \pm 1.6 \%, p=0.21)$ and $\mathrm{HR}(0.9565 \pm$ $7.3173, p=0.62$ ) was measured. Figure 3 illustrates the total $\mathrm{CBF}_{\text {exp }}$ reduction compared to the $\mathrm{CBF}_{\text {theor }}$ reduction for each of the 23 subjects and the average reduction for the entire study.

The mean $\mathrm{CBF}_{\text {exp }}$ decreased under CPAP by $12.5 \%$ $(66.6 \pm 63 \mathrm{ml} / \mathrm{min}, p<0.001)$, while the mean decrease in $\mathrm{CBF}_{\text {theor }}$ was $11.9 \%(62.8 \pm 54.4 \mathrm{ml} / \mathrm{min}, p<0.001)$. There was no significant difference between experimental and theoretical CBF reduction $(3.84 \pm 79 \mathrm{ml} / \mathrm{min}, p=0.40)$. No difference was found according to the sequence of measurements with or without CPAP, gender, height, weight, or BMI. No significant differences were found also between the left and right side US measurements of each arterial vessel. Agreement between final investigators results for CBF reduction in every subject was $87 \%$ (95\% confidence interval 0.73-0.97).

\section{Discussion}

We observed that CPAP applied at $15 \mathrm{~cm} \mathrm{H}_{2} \mathrm{O}$ significantly decreased the total $\mathrm{CBF}$ in healthy awake volunteers. The change in $\mathrm{CBF}$ was studied using a method that integrates ultrasound measurements of blood FV and arterial lumen diameter obtained at the left and right ICA, VA, and MCA. 
Fig. 1 Flow velocity (a) and vessel diameter in M-mode ultrasound (b) measured at the right ICA
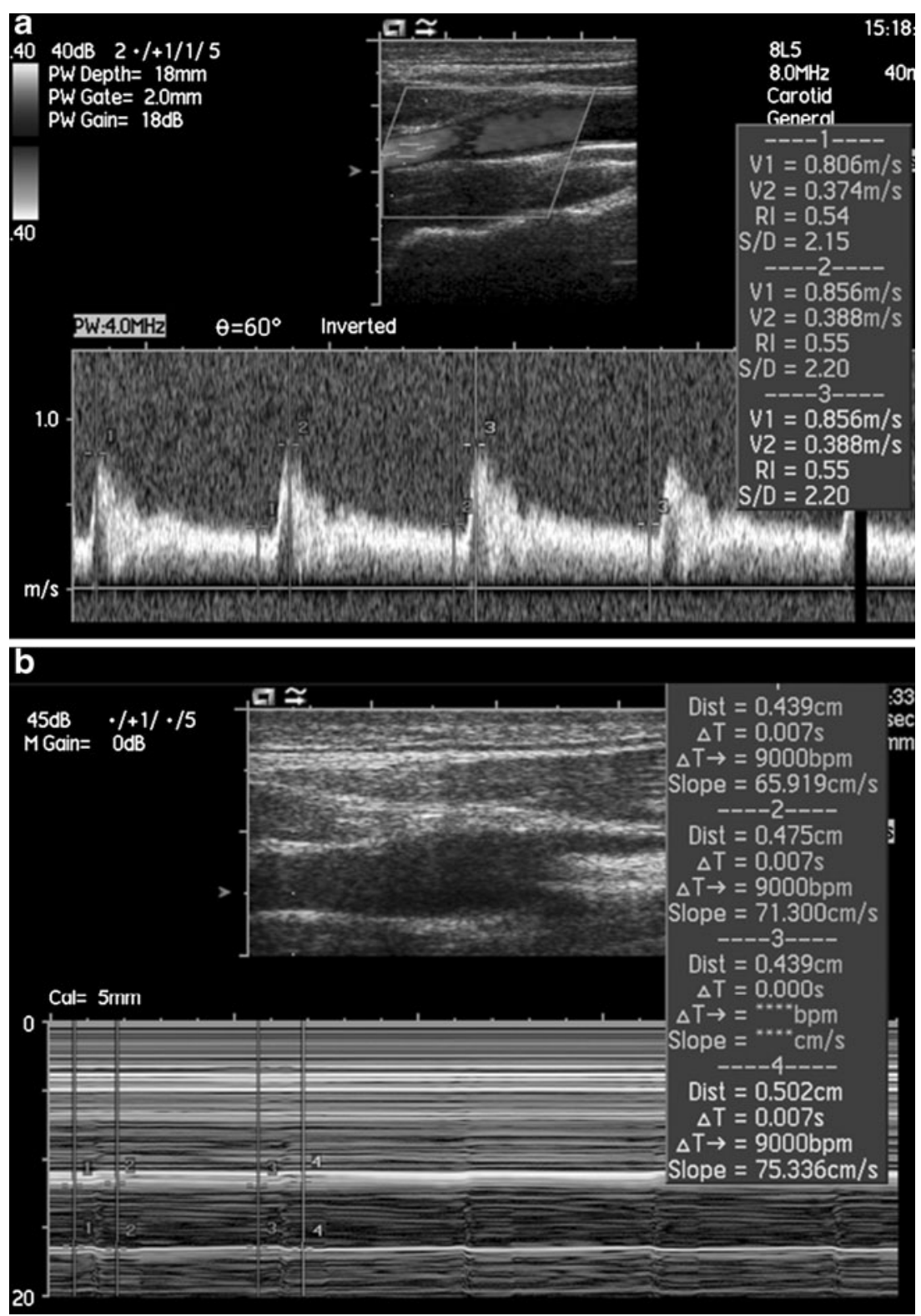

Previous studies measured FV and PI in the MCA with the hypothesis that these parameters were a good indicator of total CBF [6-10]. Thus, the arterial diameter was assumed to remain stable [4]. Table 3 summarizes the main technical characteristics and results of the previous studies that investigated the effect of CPAP on CBF hemodynamics. We chose to evaluate total CBF based on the arterial diameter and FV measured in each of the primary vessels that supply blood to the brain (ICAs and VAs). Measurement of diameter and FV in these vessels has been proposed to be a more accurate and detailed method to help estimate total CBF [22].

In our study, we chose to monitor $\mathrm{PCO}_{2}$ transcutaneously because it avoids the confounding dilution effect of end-tidal $\mathrm{CO}_{2}$ measurements that occurs due to the mixing of expired
$\mathrm{CO}_{2}$ with incoming $\mathrm{CO}_{2}$-free CPAP airflow. However, endtidal PCO2 monitoring has also several advantages, such as the quick response under provocative conditions as well as the fact it provides detailed information about the breathing pattern (i.e., respiratory rate). In the case of end-tidal $\mathrm{PCO} 2$ monitoring, the problem of $\mathrm{CO} 2$ dilution in the mask under CPAP could be avoided by the insertion of a thin catheter into one nostril far from the expiratory port [7, 23].

The underlying physiological mechanism that results in CBF change due to CPAP usage is complex. A CPAPinduced increase in intrathoracic pressure may provoke hemodynamic effects (i.e., reduced cardiac output, reduced venous return, increased cerebral venous pressure) that could result in a decrease of cerebral perfusion pressure and CBF. On the other hand, it is well accepted that $\mathrm{PCO}_{2}$ 


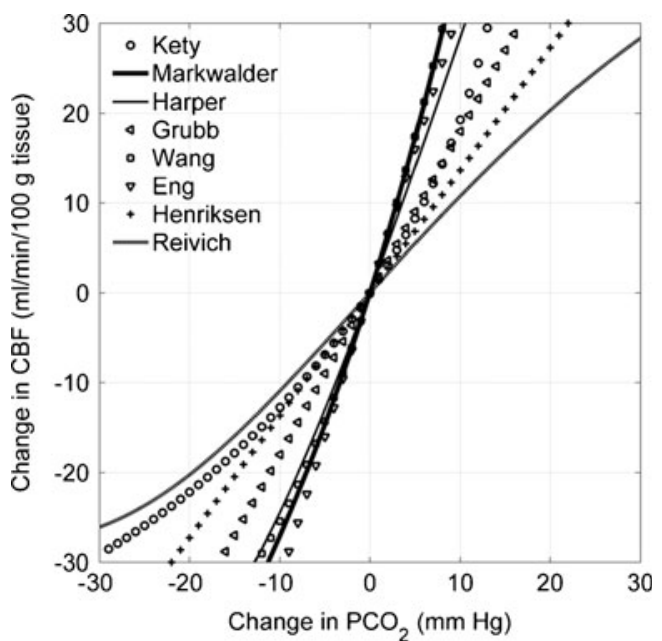

Fig. 2 Relation for change in $\mathrm{CBF}(\mathrm{ml} / \mathrm{min} / 100 \mathrm{~g}$ brain tissue) given a change in $\mathrm{PCO}_{2}(\mathrm{~mm} \mathrm{Hg})$ based on studies in the literature $[3,15-21]$

affects the muscular regulation of the arterial wall, with hypercapnia leading to vasodilatation and hypocapnia to

Table 1 Summary of CBF to $\mathrm{PCO}_{2}$ slopes reported in the literature for different animal types and $\mathrm{CBF}$ measurement techniques $\left(\mathrm{N}_{2} \mathrm{O}\right.$ nitrous oxide, $\mathrm{NO}$ nitric oxide, $\mathrm{Kr}^{85}$ radioactive krypton, $\mathrm{H}_{2}{ }^{15} \mathrm{O}$ transit diffusible tracer), Cerebral venous flowmeter (CVF), Intraarterial 133Xe

\begin{tabular}{llll}
\hline Investigator & Animal type & $\begin{array}{l}\mathrm{CBF} \\
\text { measurement } \\
\text { technique }\end{array}$ & $\begin{array}{l}\text { Slope } \\
(\triangle C B F / \triangle P C O 2) \\
\text { at baseline } \mathrm{PCO}_{2}\end{array}$ \\
\hline Kety [15] & Man & $\mathrm{N}_{2} \mathrm{O}$ & 1.47 \\
Markwalder [3] & Man & Doppler & 3.12 \\
Wasserman [17, 30] & Man & $\mathrm{N}_{2} \mathrm{O}$ & 2.17 \\
Eng [19] & Man & $\mathrm{NO}$ & 3.20 \\
Henriksen [20] & Man & ${ }^{133} \mathrm{Xe}$ & 1.36 \\
White [31], & Man & $\mathrm{N}_{2} \mathrm{O}$ & 1.34 \\
Lambertsen [32] & & & \\
Alexander [33] & Man & $\mathrm{Kr}^{85}$ & 1.06 \\
Pierce [34] & Man & $\mathrm{N}_{2} \mathrm{O}$ & 0.43 \\
Grubb [17] & Monkey & $\mathrm{H}_{2}{ }^{15} \mathrm{O}$ & 1.80 \\
Reivich [21] & Monkey & $\mathrm{Thermistor}{ }^{8}$ & 1.11 \\
White [31] & Monkey & $\mathrm{CVF}^{8}$ & 1.11 \\
Harper [16] & Dog & $\mathrm{Kr}^{85}$ & 2.69 \\
Raichle [37] & Dog & $\mathrm{Kr}^{85}$ & 0.90 \\
Fujishima [38] & Dog & $\mathrm{N}_{2} \mathrm{O}$ & 0.19 \\
Smith [36] & Goat & $\mathrm{Kr}^{85}$ & 1.79 \\
James [35] & Baboon & $\mathrm{Kr}^{85}$ & 1.22 \\
Wang [18] & Rat & $\mathrm{NO}^{85}$ & 3.10 \\
& & &
\end{tabular}

Table 2 Hemodynamic results for the 23 volunteers with and without CPAP. All values are expressed as mean (SD)

\begin{tabular}{lccc}
\hline & No CPAP (SD) & CPAP (SD) & $p$ Value \\
\hline $\mathrm{BP}(\mathrm{mmHg})$ & $87.3(6.6)$ & $90(7.1)$ & 0.0017 \\
$\mathrm{HR}$ & $68.8(10.6)$ & $69.7(12)$ & 0.62 \\
$\mathrm{PtcCO}_{2}(\mathrm{~mm} \mathrm{Hg})$ & $36.3(5.3)$ & $33.7(6.2)$ & $<0.001$ \\
$\mathrm{SaO}_{2}(\%)$ & $97.5(1.2)$ & $97.9(1.3)$ & 0.21 \\
$\mathrm{FV}_{\mathrm{ICA}}(\mathrm{m} / \mathrm{s})$ & $0.48(0.07)$ & $0.43(0.06)$ & 0.0002 \\
$\mathrm{FV}_{\mathrm{VA}}(\mathrm{m} / \mathrm{s})$ & $0.31(0.05)$ & $0.30(0.05)$ & 0.25 \\
$\mathrm{FV}_{\mathrm{MCA}}(\mathrm{m} / \mathrm{s})$ & $0.65(0.12)$ & $0.62(0.12)$ & 0.009 \\
$\mathrm{PI}_{\mathrm{ICA}}$ & $0.98(0.18)$ & $0.97(0.22)$ & 0.76 \\
$\mathrm{PI}_{\mathrm{VA}}$ & $1.20(0.18)$ & $1.21(0.18)$ & 0.92 \\
$\mathrm{PI}_{\mathrm{MCA}}$ & $0.78(0.1)$ & $0.82(0.1)$ & 0.12 \\
$\bar{D}_{\mathrm{ICA}}(\mathrm{mm})$ & $4.13(0.6)$ & $4.07(0.6)$ & 0.14 \\
$\bar{D}_{\mathrm{VA}}(\mathrm{mm})$ & $2.98(0.4)$ & $2.85(0.4)$ & $<0.001$ \\
$\mathrm{CBF}(\mathrm{ml} / \mathrm{min})$ & $535(122.1)$ & $468.5(105.6)$ & $<0.001$ \\
\hline
\end{tabular}

$C P A P$ continuous positive airway pressure, $B P$ blood pressure, $H R$ heart rate, $\mathrm{PtcCO}_{2}$ transcutaneous carbon dioxide level, $\mathrm{SaO}_{2}$ oxygen saturation, $F V$ flow velocity, $P I$ pulsatility index, $D$ diameter, $C B F$ cerebral blood flow, $S D$ standard deviation

vasoconstriction. The relative contribution of CPAPinduced changes, such as intrathoracic pressure and $\mathrm{PCO}_{2}$ level, to CBF change is unknown.

Our results supported that $\mathrm{CBF}$ reduction due to CPAP usage was primarily mediated through hypocapnic vasoconstriction. CPAP-induced intrathoracic pressure and venous hemodynamic changes did not appear to play an important role in $\mathrm{CBF}$ reduction. To determine the theoretical $\mathrm{CBF}$ effect of variation in $\mathrm{PCO}_{2}$ level with and without CPAP, we used the average value of the slope of the CBF responsiveness to acute change in $\mathrm{PCO}_{2}$ reported in the literature (Table 1). The difference between the theoretically predicted and experimentally measured change in $\mathrm{CBF}$ was not found to be significant (Fig. 3). This suggests that the theoretical prediction of the $\mathrm{CBF}$ decrease, which takes into account only the monitored $\mathrm{PtcCO}_{2}$ level, was sufficient to capture the $\mathrm{CBF}$ changes that were observed. Thus, an increase in intrathoracic pressure alone did not appear to play a significant role in $\mathrm{CBF}$ alteration.

This study cannot conclude if CPAP pressure had a direct impact on total CBF. This is because the statistical calculation used to determine that intrathoracic pressure increase did not have a significant impact on total CBF was critically dependent on the assumed slope for change in $\mathrm{CBF}$ to $\mathrm{PCO}_{2}$ level. A wide range of slope values have been reported in the literature (Table 1, slope $=0.19-3.20$ ) and thus it is possible that the theoretical predictions over or underestimated CBF change. For example, if the slope used to determine the theoretical change in $\mathrm{CBF}$ was chosen to be $<1.1$, the impact of CPAP pressure would have been found to be significant. 
Fig. 3 Comparison of the total $\mathrm{CBF}$ reduction (millimeter per minute) under CPAP, $\triangle \mathrm{CBF}_{\text {exp }}$, with the predicted theoretical reduction in $\mathrm{CBF}, \triangle \mathrm{CBF}_{\text {theor }}$, for each of the 23 subjects (left) and the average value for $\mathrm{CBF}$ reduction in all subjects (right)
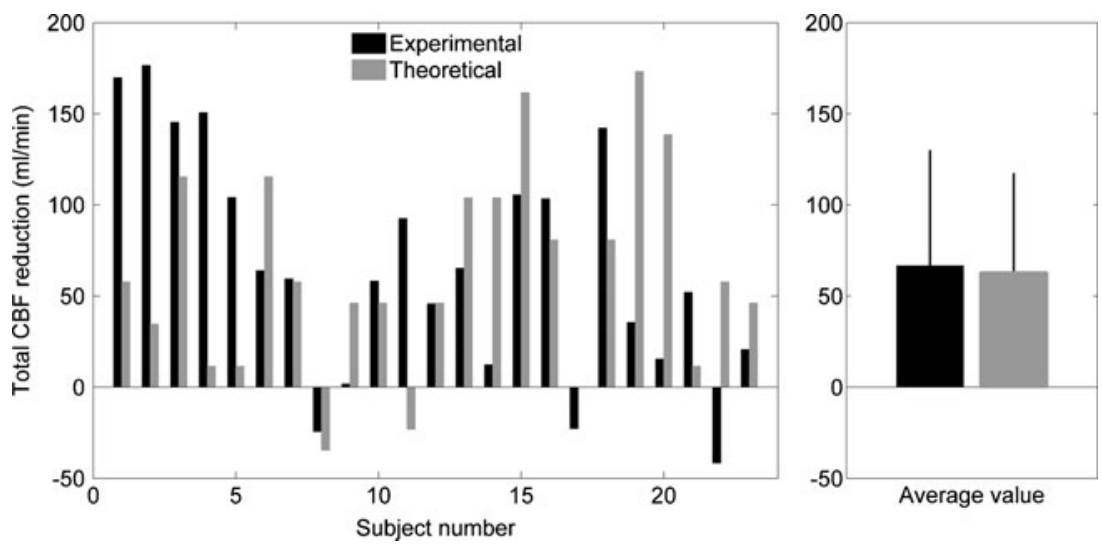

To better understand the impact, if any, of intrathoracic pressure alterations brought on by CPAP usage on CBF, a study would need to be conducted with the $\mathrm{PCO}_{2}$ level held constant while CPAP pressure is altered incrementally.

It appears that CPAP may decrease total CBF in healthy awake volunteers indirectly by modulating the $\mathrm{PCO}_{2}$ level. However, the physiological mechanism for decrease of $\mathrm{PCO}_{2}$ under CPAP is unclear. Our findings show a significant increase in BP under CPAP. This may be due to the autoregulation of systemic BP which seeks to maintain stable $\mathrm{CBF}$ [24]. Similarly, $\mathrm{SaO}_{2}$ in the healthy range has little effect on the radius of blood vessels and subsequently on CBF [25]. One hypothesis for the change in total $\mathrm{CBF}$ is that CPAP improves the lung perfusion/ventilation ratio, which may increase $\mathrm{CO}_{2}$ washout. Another explanation could be that the subjects experienced a mild hyperventilation due to anxiety induced by breathing against the CPAP. In our study, anxiety was not measured, but our measurements were obtained after an acclimatization period. It is also possible that anxiety had a direct influence on $\mathrm{CBF}$.

Changes in CBF induced by CPAP could have important clinical implications in patients requiring an optimal and stable CBF such as acute stroke patients. The question of CPAP use in early stroke patients with OSAS remains open considering the positive effect of CPAP on apnea-induced oxygen deprivation versus possible negative effects of CPAP, such as reduction of total CBF. A specific study would need to be performed to examine the impact of CPAP pressure on $\mathrm{CBF}$ in stroke patients to validate these conjectures.

A primary limitation of this study is that the subjects who were tested were both healthy and awake. Subjects who are awake may react differently to CPAP than sleeping OSAS patients. However, these measurements could not be obtained on sleeping subjects, as these measurements would awaken them, and variable comorbidities (e.g., obesity, heart failure, medication) would make comparison between the subjects' results unreliable. Furthermore, our results

Table 3 Summary of the main technical features of the studies in the literature that investigated the impact of CPAP on CBF hemodynamics

\begin{tabular}{|c|c|c|c|c|c|c|c|c|}
\hline Investigator & $\begin{array}{l}\text { Level of CPAP } \\
\left(\mathrm{cm} \mathrm{H} \mathrm{H}_{2} \mathrm{O}\right)\end{array}$ & $\begin{array}{l}\text { No of subjects/ } \\
\text { health condition }\end{array}$ & $\begin{array}{l}\text { Position of the } \\
\text { subject/type of } \\
\text { CPAP mask }\end{array}$ & $\begin{array}{l}\text { US } \\
\text { measurement } \\
\text { technique }\end{array}$ & $\begin{array}{l}\text { CBF measurement } \\
\text { technique }\end{array}$ & $\begin{array}{l}\mathrm{PCO}_{2} \\
\text { measurement }\end{array}$ & $\begin{array}{l}\text { Hemodynamic } \\
\text { monitoring }\end{array}$ & Results \\
\hline Bowie et al. [6] & 5,10 & 15 awake/healthy & Supine/mouthpiece & TCD & FV on MCA & End-tidal $\mathrm{CO}_{2}$ & $\mathrm{BP}$ & $\begin{array}{l}\text { No significant } \\
\text { change }\end{array}$ \\
\hline Scala et al. [7] & $5,10,15$ & 25 awake/healthy & Supine/mouthpiece & TCD & $\mathrm{FV}$ on $\mathrm{MCA}$ & End-tidal $\mathrm{CO}_{2}$ & $\begin{array}{l}\mathrm{BP}, \mathrm{HR}, \mathrm{RR}, \\
\mathrm{SaO}_{2} \text {, anxiety } \\
\text { score }\end{array}$ & Decrease of FV \\
\hline Scala et al. [23] & $\begin{array}{l}\text { Auto-CPAP mode } \\
(4-10) \text { and } \\
\text { increasing } \\
\text { levels of } \\
5,10,15\end{array}$ & $\begin{array}{c}12 \text { asleep and } \\
\text { awake/acute } \\
\text { stroke patients }\end{array}$ & $\begin{array}{l}\text { Supine/nasal } \\
\text { or facial }\end{array}$ & TCD & $\mathrm{FV}$ on $\mathrm{MCA}$ & End-tidal $\mathrm{CO}_{2}$ & $\mathrm{BP}, \mathrm{SaO}_{2}$ & $\begin{array}{c}\text { Decrease } \\
\text { of FV }\end{array}$ \\
\hline Haring et al. [8] & 12 & 9 awake/healthy & Supine/mouthpiece & TCD & FV on MCA & End-tidal $\mathrm{CO}_{2}$ & BP, HR & Increase of FV \\
\hline Present study & 15 & 23 awake/healthy & Supine/mouthpiece & $\begin{array}{l}\text { Duplex color } \\
\text { Doppler US }\end{array}$ & $\begin{array}{l}\text { FV and lumen } \\
\text { diameter of } \\
\text { ICA, VA } \\
\text { and FV on } \\
\text { MCA }\end{array}$ & $\begin{array}{l}\text { Transcutaneous } \\
\mathrm{PtcCO}_{2}\end{array}$ & $\mathrm{BP}, \mathrm{HR}, \mathrm{SaO}_{2}$ & $\begin{array}{l}\text { Decrease } \\
\text { of CBF }\end{array}$ \\
\hline
\end{tabular}

$C P A P$ continuous positive airway pressure, $\mathrm{BP}$ blood pressure, $\mathrm{HR}$ heart rate, $\mathrm{PtcCO}_{2}$ transcutaneous carbon dioxide level, $\mathrm{SaO}_{2}$ oxygen saturation, $F V$ flow velocity, $C B F$ cerebral blood flow, $R R$ respiratory rate 
suggest that non-invasive techniques that could be conducted during sleep, such as transcranial Doppler ultrasound obtained at the MCAs, may not be sufficient to measure the changes in CBF that were observed (Table 1). In our study, measurement of FV and diameter at all vessels supplying blood to the brain was needed to detect the CBF changes. In a multivariate robust regression with total $\mathrm{CBF}$ reduction as a dependent variable, only ICA FV remained significant. From a clinical point of view, this result justifies the fact that a bedside sampling of this parameter could more easily approximate total CBF, something that could be less time consuming especially in the case of patients such as acute stroke patients or OSAS patients with ischemic encephalopathy. It would be very interesting for future studies to examine this US approach on the aforementioned clinical population.

A secondary limitation of this study is that even though the assignment to spontaneous breathing or to CPAP was based on a randomized order following a structured protocol, a "breathing-machine effect" could not be excluded [26]. However, the protocol was set to evaluate the global impact of the CPAP (mask in combination with pressurized air) to cerebral hemodynamics as a mainstay therapy of OSAS. To further understand the effect of the CPAP mask and that of the CPAP mask and pressurized air using "sham ventilation", a separate study should be conducted focused on the potential effect of the mask itself on the breathing pattern independently from the pressurized air.

Another limitation of this study is that CPAP was adjusted at the high level of $15 \mathrm{~cm} \mathrm{H}_{2} \mathrm{O}$. Haring et al. [8] and Droste et al. [27] submitted volunteers to CPAP 12 and $9 \mathrm{~cm} \mathrm{H}_{2} \mathrm{O}$, respectively whereas Bowie et al. [6] and Scala et al. [7] studied the effects of different and increasing levels of CPAP on CBF. In our study, we applied CPAP of $15 \mathrm{~cm} \mathrm{H}_{2} \mathrm{O}$ in young healthy awake volunteers. This high level of CPAP is rarely used in controlling patients with sleep disordered breathing. CPAP at $15 \mathrm{~cm} \mathrm{H}_{2} \mathrm{O}$ was useful in the experimental setting of our study in order to underline the maximum physiological effects of CPAP on cerebral hemodynamics by minimizing possible bias. The level of CPAP was set at $15 \mathrm{~cm} \mathrm{H}_{2} \mathrm{O}$ on the machine. It is possible that this high pressure could have resulted in substantial air leaks and caused a gap between the applied and delivered mask pressure and subsequently increased subject discomfort [28, 29]. However, during the ultrasound measurements of our study the presence of air leaks was repeatedly assessed by the MD and adjusted when needed. All volunteers tolerated well the mask with CPAP at $15 \mathrm{~cm} \mathrm{H}_{2} \mathrm{O}$.

Another limitation of this study is due to the operator dependence of the measurements used to determine CBF. To minimize operator-dependent error, both operators that conducted the vessel lumen measurements reviewed the US images together after the measurements were made. This review helped to assure that the correct vessel and the same acquisition period were used for the diameter measurements. With this precaution, a good agreement score was found.

In addition to operator-dependent error, our study utilized equations to calculate blood flow based on simplified hydrodynamics. To calculate total $\mathrm{CBF}$, it was assumed that zero phase delay occurred between the arrival of the $\mathrm{FV}_{\text {sys }}$ at the ICA and VA and that a parabolic velocity profile was present to determine the true flow rate within the vessels [14]. To minimize measurement error, the mean flow in each vessel was approximated using the average of three sequential diastolic and systolic FV and diameter measurements. Even with these simplifications, the presented methodology is robust because it is sensitive to changes in $\mathrm{CBF}$, the measurement of which was the primary objective of this study.

In conclusion, our study presents a noninvasive bedside method to evaluate total CBF in awake subjects using CPAP that could potentially be an improvement over other methods which only take into account FV at the MCA. The results suggest that $\mathrm{CPAP}$ at $15 \mathrm{~cm} \mathrm{H}_{2} \mathrm{O}$ significantly decreases CBF in healthy, awake volunteers. This effect seems to be mediated predominately through the hypocapnic vasoconstriction and likely, to a lesser extent, through the direct effect of CPAP on intrathoracic pressure and venous hemodynamics. These results suggest that CPAP should be cautiously used in patients with unstable cerebral hemodynamics.

Acknowledgments The authors are indebted to all volunteers whose participation made this study possible. This study was funded by the Swiss National Science Foundation Grant 205321_132695/1.

\section{References}

1. Buda AJ, Pinsky MR, Ingels NB Jr, Daughters GT 2nd, Stinson EB, Alderman EL (1979) Effect of intrathoracic pressure on left ventricular performance. N Engl J Med 301(9):453-459. doi:10.1056/NEJM197908303010901

2. Becker H, Grote L, Ploch T, Schneider H, Stammnitz A, Peter JH, Podszus T (1995) Intrathoracic pressure changes and cardiovascular effects induced by nCPAP and nBiPAP in sleep apnoea patients. J Sleep Res 4(S1):125-129

3. Markwalder TM, Grolimund P, Seiler RW, Roth F, Aaslid R (1984) Dependency of blood flow velocity in the middle cerebral artery on end-tidal carbon dioxide partial pressure-a transcranial ultrasound Doppler study. J Cereb Blood Flow Metab 4(3):368-372

4. Valdueza JM, Draganski B, Hoffmann O, Dirnagl U, Einhaupl KM (1999) Analysis of CO2 vasomotor reactivity and vessel diameter changes by simultaneous venous and arterial Doppler recordings. Stroke 30(1):81-86

5. Eicke BM, Buss E, Bahr RR, Hajak G, Paulus W (1999) Influence of acetazolamide and $\mathrm{CO} 2$ on extracranial flow volume and intracranial blood flow velocity. Stroke 30(1):76-80 
6. Bowie RA, O'Connor PJ, Hardman JG, Mahajan RP (2001) The effect of continuous positive airway pressure on cerebral blood flow velocity in awake volunteers. Anesth Analg 92(2):415-417

7. Scala R, Turkington PM, Wanklyn P, Bamford J, Elliott MW (2003) Effects of incremental levels of continuous positive airway pressure on cerebral blood flow velocity in healthy adult humans. Clin Sci (Lond) 104(6):633-639. doi:10.1042/CS20020305

8. Haring HP, Hormann C, Schalow S, Benzer A (1994) Continuous positive airway pressure breathing increases cerebral blood flow velocity in humans. Anesth Analg 79(5):883-885

9. Klingelhofer J, Hajak G, Sander D, Schulz-Varszegi M, Ruther E, Conrad B (1992) Assessment of intracranial hemodynamics in sleep apnea syndrome. Stroke 23(10):1427-1433

10. Netzer N, Werner P, Jochums I, Lehmann M, Strohl KP (1998) Blood flow of the middle cerebral artery with sleep-disordered breathing: correlation with obstructive hypopneas. Stroke 29 (1):87-93

11. Schoning M, Walter J, Scheel P (1994) Estimation of cerebral blood flow through color duplex sonography of the carotid and vertebral arteries in healthy adults. Stroke: A Journal of Cerebral Circulation 25(1): 17-22

12. Harloff A, Strecker C, Reinhard M, Kollum M, Handke M, Olschewski M, Weiller C, Hetzel A (2006) Combined measurement of carotid stiffness and intima-media thickness improves prediction of complex aortic plaques in patients with ischemic stroke. Stroke 37(11):2708-2712

13. Tominaga S, Strandgaard S, Uemura K, Ito K, Kutsuzawa T (1976) Cerebrovascular $\mathrm{CO} 2$ reactivity in normotensive and hypertensive man. Stroke 7(5):507-510

14. Leguy CA, Bosboom EM, Hoeks AP, van de Vosse FN (2009) Model-based assessment of dynamic arterial blood volume flow from ultrasound measurements. Med Biol Eng Comput 47(6):641648. doi:10.1007/s11517-009-0473-9

15. Kety SS, Schmidt CF (1948) The effects of altered arterial tensions of carbon dioxide and oxygen on cerebral blood flow and cerebral oxygen consumption of normal young men. J Clin Invest 27 (4):484-492

16. Harper AM, Glass HI (1965) Effect of alterations in arterial carbon dioxide tension on blood flow through cerebral cortex at normal and low arterial blood pressures. J Neurol Neurosur Ps 28(5):449452

17. Grubb RL Jr, Raichle ME, Eichling JO, Ter-Pogossian MM (1974) The effects of changes in $\mathrm{PaCO} 2$ on cerebral blood volume, blood flow, and vascular mean transit time. Stroke 5(5):630-639

18. Wang Q, Paulson OB, Lassen NA (1992) Effect of nitric-oxide blockade by N-G-nitro-L-arginine on cerebral blood-flow response to changes in carbon-dioxide tension. J Cerebr Blood F Met 12 (6):947-953

19. Eng C, Lam A, Mayberg T, Mathison T, Lee C (1992) The influence of propofol with and without nitrous-oxide on cerebral blood-flow velocity and Co2 reactivity in man. Stroke 23(3):456456

20. Henriksen L (1986) Brain luxury perfusion during cardiopulmonary bypass in humans - a study of the cerebral blood-flow response to changes in Co2, O-2, and blood pressure. J Cerebr Blood F Met 6(3):366-378

21. Reivich M (1964) Arterial Pco2 and cerebral hemodynamics. Am J Physiol 206:25-35
22. Kontos HA (1989) Validity of cerebral arterial blood flow calculations from velocity measurements. Stroke 20(1):1-3

23. Scala R, Turkington PM, Wanklyn P, Bamford J, Elliott MW (2009) Acceptance, effectiveness and safety of continuous positive airway pressure in acute stroke: a pilot study. Respir Med 103 (1):59-66. doi:10.1016/j.rmed.2008.08.002

24. Schmidt JF, Waldemar G, Vorstrup S, Andersen AR, Gjerris F, Paulson OB (1990) Computerized analysis of cerebral blood flow autoregulation in humans: validation of a method for pharmacologic studies. J Cardiovasc Pharmacol 15(6):983-988

25. Guyton AC (1991) Textbook of medical physiology, 8th edn. Saunders, Philadelphia

26. Stroobant N, Vingerhoets G (2000) Transcranial Doppler ultrasonography monitoring of cerebral hemodynamics during performance of cognitive tasks: a review. Neuropsychol Rev 10 (4):213-231

27. Droste DW, Ludemann P, Anders F, Kemeny V, Thomas M, Krauss JK, Ringelstein EB (1999) Middle cerebral artery blood flow velocity, end-tidal $\mathrm{pCO}(2)$ and blood pressure in patients with obstructive sleep apnea and in healthy subjects during continuous positive airway pressure breathing. Neurol Res 21(8):737-741

28. Navalesi P, Fanfulla F, Frigerio P, Gregoretti G, Nava S (2000) Physiologic evaluation of noninvasive mechanical ventilation delivered with three types of masks in patients with chronic hypercapnic respiratory failure. Crit Care Med 28(6):1785-1790

29. Bakker JP, Neill AM, Campbell AJ (2011) Nasal versus oronasal continuous positive airway pressure masks for obstructive sleep apnea: a pilot investigation of pressure requirement, residual disease, and leak. Sleep Breath. doi:10.1007/s11325-011-0564-3

30. Wasserman A, Patterson JL (1961) Cerebral vascular response to reduction in arterial carbon dioxide tension. J Clin Investig 40 (7):1297-1303

31. White JC, Brooks JR, Goldthwait JC, Adams RD (1943) Changes in brain volume and blood content after experimental concussion. Ann Surg 118(4):619-633

32. Lambertsen CJ, Owen SG, Wendel H, Stroud MW, Lurie AA, Lochner W, Clark GF (1959) Respiratory and cerebral circulatory control during exercise At.21 and 2.0 atmospheres inspired Po2. J Appl Physiol 14(6):966-982

33. Alexander SC, Cohen PJ, Wollman H, Smith TC, Reivich M, Vandermolen RA (1965) Cerebral carbohydrate metabolism during hypocarbia in man: studies during nitrous oxide anesthesia. Anesthesiology 26:624-632

34. Pierce EC, Linde HW, Deutsch S, Chase PE, Price HL, Lambertsen CJ, Dripps RD (1962) Cerebral circulation and metabolism during thiopental anesthesia and hyperventilation in man. J Clin Investig 41(8):1664-1671

35. James IM, Millar RA, Purves MJ (1969) Observations on extrinsic neural control of cerebral blood flow in baboon. Circ Res 25 (1):77-93

36. Smith AL, Neufeld GR, Ominsky AJ, Wollman H (1971) Effect of arterial $\mathrm{Co} 2$ tension on cerebral blood flow, mean transit time, and vascular volume. Journal of Applied Physiology 31(5):701-707

37. Raichle ME, Posner JB, Plum F (1970) Cerebral blood flow during and after hyperventilation. Arch Neurol-Chicago 23(5):394-403

38. Fujishima M, Scheinberg P, Busto R, Reinmuth OM (1971) The relation between cerebral oxygen consumption and cerebral vascular reactivity to carbon dioxide. Stroke 2(3):251-257 